Marquette University

e-Publications@Marquette

Psychology Faculty Research and Publications

Psychology Department

$3-1-2001$

Intact Physiological Response to Arousal with Impaired Emotional Recognition in Alexithymia

Linda Ann Stone

Marquette University

Kristy A. Nielson

Marquette University, kristy.nielson@marquette.edu

Accepted version. Psychotherapy and Psychosomatics, Vol. 70, No. 2 (March/April 2001): 92-102.

DOI. (C) 2001 Karger. Used with permission. 


\title{
Intact Physiological Response To Arousal With Impaired Emotional Recognition In Alexithymia
}

\author{
Linda A. Stone \\ Department of Psychology, Marquette University, \\ Foley Center for Aging and Development, Department of \\ Psychiatry and Behavioral Medicine, \\ Medical College of Wisconsin, \\ Milwaukee, WI \\ Kristy A. Nielson \\ Department of Psychology, Marquette University, \\ Milwaukee, WI
}

\begin{abstract}
Background: The purpose of the present study was to clarify the relationship between the recognition of emotion and physiological response to emotion (i.e. arousal) in alexithymia. Methods: This study investigated differences in physiological arousal state, as measured by continuous heart rate, electrodermal activity (EDA) and self-reported emotional intensity before and
\end{abstract}

Psychotherapy and Psychosomatics, Vol 70, No. 2 (March/April 2001): pg. 92-102. DOI. This article is @ Karger and permission has been granted for this version to appear in e-Publications@Marquette. Karger does not grant permission for this article to be further copied/distributed or hosted elsewhere without the express permission from Karger. 
after exposure to an emotionally arousing or neutral videotape among 41 high- or low-alexithymic young adult participants. Results: Across subjects, emotionally negative stimuli produced increased physiological arousal. However, high-alexithymic participants exposed to the arousing videotape did not report increased subjective emotional intensity, as did low-alexithymic participants. In addition, the baseline EDA of high-alexithymic participants was significantly higher than that of the low-alexithymic participants.

Conclusions: Results support the prediction that alexithymia leads to a decoupling between subjective and physiological arousal when exposed to emotionally negative stimuli. This decoupling may increase alexithymic individuals' risks for stress-related illness.

Key Words: Autonomic arousal, Alexithymia, Subjective emotion Psychophysiology, Electrodermal activity, Stress-related illness

\section{I ntroduction}

The term alexithymia, originally introduced by Sifneos, ${ }^{1}$ is used to describe a cluster of characteristics that includes difficulty identifying, describing and communicating feelings; difficulty distinguishing between feelings and bodily sensations; constricted imaginal processes, and an externally oriented cognitive style. ${ }^{2-5}$ Alexithymia is considered a personality risk factor for a variety of medical and psychiatric disorders, ${ }^{6}$ including chronic headaches, ${ }^{7}$ essential hypertension, ${ }^{8}$ eating disorders, ${ }^{9,10}$ substance abuse ${ }^{11}$ and alcohol abuse. ${ }^{12}$ Although the etiology of alexithymia is as yet unknown, Taylor ${ }^{6}$ postulated that the link between alexithymia and increased risk for stress-related disorders is based on emotional dysregulation.

Emotion allows successful adaptation to change by providing accurate information and motivating appropriate behavior. ${ }^{13}$ Human emotional responses consist of several components, including neurophysiological (e.g. autonomic nervous system and neuroendocrine activation), motor- and behavior-expressive (e.g. facial expressions, changes in tone of voice or posture) and cognitive-experiential components (e.g. subjective awareness and reporting emotions). ${ }^{14}$ Nemiah and Sifneos ${ }^{15}$ proposed a deficit model of alexithymia in which the inability to symbolize and express emotion through words, fantasy and dreams produces a variety of dysfunctional characteristics, including abnormal physiology, that can result in disease. Indeed, studies examining the impact of emotional 
expression on health report that the disclosure of stressful events is associated with reduced autonomic arousal ${ }^{16}$ and fewer physician visits for illness. ${ }^{17}$ While research into the basis for such an emotion processing deficit continues, ${ }^{18-20}$ several theories have addressed the specific physiological link between the inability to recognize and express emotions, alexithymia and stress-related disorders.

Martin and Pihl's ${ }^{21}$ stress-alexithymia hypothesis proposed that the alexithymic individual's inaccurate identification of the emotional basis of physiological arousal during a stressful situation increases the probability of prolonged exposure to the stressor. Consistent with the research demonstrating reduced autonomic arousal following selfdisclosure, ${ }^{16}$ the stress-alexithymia hypothesis suggests that the inability to express emotions results in persistently high levels of autonomic activity in alexithymia. ${ }^{21}$ Prolonged activation of the hypothalamic-pituitary-adrenal (HPA) axis, with consistently higher levels of circulating adrenal hormones related to unresolved arousal, may lead to stress-related medical and behavioral problems and symptoms, such as dysphoric hyperarousal, relative immunosuppression and colonic hypermotility. ${ }^{22}$

In contrast to the elevated physiological arousal predicted by the stress-alexithymia hypothesis, ${ }^{21}$ Papciak et al. ${ }^{23}$ proposed the existence of a 'decoupling' between peripheral physiological activity and subjective emotional awareness in alexithymia. According to the decoupling hypothesis, alexithymia produces a level of physiological reaction to stressors similar to that seen in non-alexithymia. However, alexithymia is accompanied by a decreased ability to recognize and report subjective emotions that, similar to the stress-alexithymia hypothesis, results in prolonged exposure to stressors and increased risk for stress-related disorder. ${ }^{23}$ Taylor $^{6}$ later proposed that alexithymia-related illnesses be viewed as disorders of emotion regulation that result from purported exacerbated, ${ }^{21}$ as well as prolonged $^{21,23}$ autonomic and neuroendocrine responses. Due to the important association of alexithymia with a number of stress-related illnesses, ${ }^{7,8,10}$ research continues to explore the connection between emotional dysregulation, physiological arousal and alexithymia.

Overall, studies support the existence of higher sympathetic activation in alexithymia, but they do so inconsistently across indices.

Psychotherapy and Psychosomatics, Vol 70, No. 2 (March/April 2001): pg. 92-102. DOI. This article is @ Karger and permission has been granted for this version to appear in e-Publications@Marquette. Karger does not grant permission for this article to be further copied/distributed or hosted elsewhere without the express permission from Karger. 
That is, some studies have demonstrated a higher tonic heart rate (HR), ${ }^{23-25}$ while others have shown higher tonic electrodermal activity (EDA). ${ }^{26}$ Of the three studies to date that measured both indices, one reported only an elevated baseline $\mathrm{HR},{ }^{25}$ one reported only elevated $\mathrm{EDA}^{26}$ and the last reported no tonic differences between alexithymic and nonalexithymic participants. ${ }^{27}$ Though somewhat inconsistent, these findings generally support the hypothesis that alexithymia may result in higher levels of baseline physiological arousal. 6,21

Research has also provided some support for the existence of the decoupling of physiological arousal and emotion recognition in alexithymia. However, this support has been both indirect and inconsistent. Two of the earliest studies, which provided evidence of elevated resting HR in alexithymia, also provided some evidence of decoupling of physiological response and subjective report. Despite the baseline differences, in both studies physiological responses to stressors were comparable in alexithymic versus nonalexithymic participants. ${ }^{23,24}$ However, Papciak et al. ${ }^{23}$ found relatively reduced selfreported post-task tension, while Martin and $\mathrm{Pihl}^{24}$ found relatively increased self-reported post-task stress compared to non-alexithymic participants. These inconsistencies may be due to the use in both studies of an alexithymia measure that is less than optimal (SchallingSifneos Personality Scale). ${ }^{28,29}$ However, later studies that utilized the more psychometrically sound Toronto Alexithymia Scale (TAS) ${ }^{30}$ continued to produce mixed results.

Using the TAS to assess alexithymia, some researchers have found indirect support for a decoupling phenomenon in alexithymia. For instance, one study found comparable physiological reactions during stressful tasks in alexithymia, but higher self-reported displeasure during relaxation. ${ }^{26}$ Another study showed higher baseline EDA in alexithymia, but general self-reported mood (i.e. nonspecific to any particular task) was comparable to that of low-- alexithymic participants. ${ }^{31}$ Another recent study found elevated levels of sympathetic activity (EDA) in alexithymic psychiatric patients during stressful tasks. ${ }^{32}$ Although subjective arousal was not assessed during the tasks, it could be suggested that this study indirectly supports a decoupling hypothesis because alexithymic participants in this clinical sample endorsed the tendency to internalize on a personality inventory. ${ }^{32}$

Psychotherapy and Psychosomatics, Vol 70, No. 2 (March/April 2001): pg. 92-102. DOI. This article is @ Karger and permission has been granted for this version to appear in e-Publications@ Marquette. Karger does not grant permission for this article to be further copied/distributed or hosted elsewhere without the express permission from Karger. 
In contrast to the several studies showing some support for the decoupling concept, a recent study reported that reduced sympathetic reactivity was accompanied by fewer emotion words and less variation in self-reported arousal in high-alexithymic participants presented with emotion-provoking slides. ${ }^{27}$ Therefore, the results were not consistent with a decoupling hypothesis. Rather, the results showed a reduced physiological and affective response to the slides that supports a decreased ability to process emotional information in alexithymia. ${ }^{27}$

One possibility for the inconsistency across studies in alexithymia is inter-subject variability in physiological response and insensitivity of physiological recording and analysis measures. Another possible explanation for the differences across studies may be the particular stimuli used to evoke emotional responses. In a review of empirical studies of alexithymia, Ahrens and Deffner ${ }^{33}$ suggested that subjective involvement with the stimulus might be necessary in order to obtain a more realistic emotional response. Indeed, the only study to date that reported a significantly elevated physiological response across tasks in high-alexithymic participants was one that utilized a combination of a cognitive task and an anxiety-provoking videotape. ${ }^{32}$ Studies using mentally stressful tasks elicited comparable betweengroups physiological arousal ${ }^{23,24,26,31}$ with evidence of increased stress, tension or displeasure only during relaxation after the task. ${ }^{23,24,26}$ In contrast, the two studies that used emotion-provoking slide stimuli produced the lowest relative physiological ${ }^{25,27}$ and self-reported responses ${ }^{27}$ in the high alexithymic groups. As such, the variation in previous results may, in part, be caused by variations in the emotional involvement of the subjects with the stimuli. ${ }^{33}$

The purpose of the present study was to clarify the relationship between the recognition of emotion and the physiological response to emotion (i.e. arousal) in alexithymia. Therefore, an emotionally neutral or arousing live-action videotape of commonly experienced events was used to elicit physiological (HR, EDA) and subjective emotional responses. Based upon previous research results, it was hypothesized that individuals higher in alexithymia would display higher baseline (tonic) levels of HR and EDA. It was also predicted that both high- and low-- alexithymic participants would demonstrate comparably increased levels of physiological arousal during the arousing stimulus. Finally, it was hypothesized that decoupling would occur, such that

Psychotherapy and Psychosomatics, Vol 70, No. 2 (March/April 2001): pg. 92-102. DOI. This article is @ Karger and permission has been granted for this version to appear in e-Publications@Marquette. Karger does not grant permission for this article to be further copied/distributed or hosted elsewhere without the express permission from Karger. 
high-alexithymic subjects would not be able to accurately recognize a change in subjective emotions while viewing the arousing videotape, thereby eliciting significantly less change in subjective emotion than in the low-alexithymic subjects who view the arousing videotape.

Lane and Schwartz ${ }^{34}$ suggested that a subjective emotional response instrument that provides the names of expected emotions limits the subjects' responses. Indeed, such an instrument may also provide cues for individuals who inherently have difficulty labeling emotions. Thus, the use of an open-ended instrument would be expected to yield larger differences between high- and low-alexithymic individuals in response to an emotional stimulus. In order to explore this possibility, an open-- ended question about immediate affect was presented prior to the self-report of specified negative feelings, both before and after the videotape. It was hypothesized that the highalexithymic individuals would use fewer specific emotion words in answer to the open-ended question, including fewer positive and negative affect words, than would low-alexithymic participants.

\section{Method}

\section{Participants}

After providing informed consent, 319 college students were screened using the TAS-20. ${ }^{35}$ Researchers recruited 41 ( 30 females, 11 males) students (mean, $M$, age $=19.35$, SD $=1.29$ ) whose scores fell within the first ( $<=37$ total score, $n=20,18$ females, 2 males) and fifth ( $>=54$ total score, $n=21,12$ females, 9 males) quintiles on the TAS- $20(\mathrm{Md}=45$, range $=23-75 ; \mathrm{M}=45.55, \mathrm{SD}=9.75)$. Each student was then interviewed with regard to general health, medications and recreational drug use. None of the participants reported health conditions or drug use.

\section{Self-Report Measures}

The TAS- $20^{35}$ is a 20 -item self-report questionnaire in which answers are recorded on a 5-point Likert scale ranging from 1 (strongly disagree) to 5 (strongly agree). It has good internal consistency (alpha coefficient $=0.81$ for a college sample and 0.83 for

Psychotherapy and Psychosomatics, Vol 70, No. 2 (March/April 2001): pg. 92-102. DOI. This article is @ Karger and permission has been granted for this version to appear in e-Publications@Marquette. Karger does not grant permission for this article to be further copied/distributed or hosted elsewhere without the express permission from Karger. 
a psychiatric sample) and a three-factor structure reflecting three characteristics consistent with the construct of alexithymia. These factors are: (1) difficulty identifying feelings, (2) difficulty describing feelings and (3) externally oriented thinking. Evidence of good convergent and divergent validity was demonstrated in samples of university students by a pattern of correlations with the scales of a personality inventory and separate measures of psychological mindedness and need for cognition. ${ }^{36}$ Finally, analysis of 2-month testretest reliability of the TAS-20 in the sample from the present study was $r=0.95$ (taken at initial recruitment and again upon return for study participation).

The Emotional Intensity Scale (EIS) ${ }^{37}$ is an unpublished self report measure of 14 emotions scored using a 7-point Likert scale of intensity from 1 (none at all) to 7 (extreme amount). Derived from a literature review of core emotions, ${ }^{38} 13$ negative emotions in this scale were used to detect the presence of specific negative emotions and changes in subjective intensity. 'Anxious' was deleted from the original list due to its colloquial meaning signifying positive anticipation in the Midwest. The emotions used were: worried, annoyed, depressed, sick, concerned, angry, vulnerable, sad, weary, fearful, helpless, surprised, disgusted. Analysis of the reliability coefficients for the 13 EIS items from the sample in the present study produced a Cronbach a of 0.84 , indicating good internal consistency.

The open-ended questions `Please describe how you feel at this moment' and 'Please describe how you felt while you viewed the video' were scored for total words, total affective words and the percentage of total affective words to total words, as outlined previously. ${ }^{39}$ In addition, total positive and negative affective words were assessed.

\section{Physiological Measures}

Physiological measurements consisted of EDA, as measured by skin conductance, and HR in beats per minute. Two electrodes continuously recorded EDA and a third electrode, a photoplethysmograph, measured $\mathrm{HR}$. The isolated amplifiers were connected to an analog to digital converter board in an IBM-compatible microcomputer, and the data were recorded by data acquisition 
software (Virtual Instruments MasterLab(R); Expanded Technologies, Shreveport, La., USA) at a rate of $16 \mathrm{~Hz}$.

\section{Procedure}

The study, which was performed in accordance with established ethical standards as approved by the Marquette University Institutional Review Board, consisted of one laboratory session, lasting approximately $30 \mathrm{~min}$. Experimenters assigned individuals quasirandomly (qualified only by alexithymia group) to either the neutral ( $n$ $=21 ; 11$ high-alexithymia, 8 females, 3 males; 10 low-alexithymia, 9 females, 1 male) or arousing ( $n=20 ; 10$ high-alexithymia, 4 females, 6 males; 10 low-alexithymia, 9 females, 1 male) stimulus condition, in alternating order, upon arrival. Participants were requested not to eat, smoke or drink anything except water within $2 \mathrm{~h}$ of their participation. Following a health questionnaire, sensors were applied to the nondominant hand and HR and EDA collected at 2second intervals throughout the session. A 5-min baseline physiological measurement was taken during which the subject was instructed to rest with eyes closed. The last 3 min of physiological measurement were designated as the subject's baseline. The participant then provided a written answer to the open-ended question 'Please describe how you feel at this moment' and completed the pre-video EIS.

The stimulus period consisted of a 3-min live-action videotape of either a Southwestern landscape with soft guitar music (neutral stimulus) or oral surgery with appropriate surgical sounds, i.e. drilling and suctioning (arousing stimulus). At the completion of the videotape, the participant answered the second open-ended question 'Please describe what you were feeling while you viewed the video', the postvideo EIS and another TAS- 20.

\section{Statistical Analysis}

Raw EDA and HR data were reduced to one measure per 5second interval for each index. Each was then averaged across the 3min baseline and the 3-min videotape periods for each subject. EIS consisted of a total score.

Psychotherapy and Psychosomatics, Vol 70, No. 2 (March/April 2001): pg. 92-102. DOI. This article is (c) Karger and permission has been granted for this version to appear in e-Publications@Marquette. Karger does not grant permission for this article to be further copied/distributed or hosted elsewhere without the express permission from Karger. 
The study consisted of two designs, thereby yielding two separate sets of analyses. The first analysis was based on a 2 (tape, between subjects) $\times 2$ (group, between subjects) $\times 2$ (measures, within subject) mixed design with three dependent measures of arousal: EDA, HR and EIS. Thus, multivariate analysis of variance (MANOVA) was used followed by univariate analysis of variance (ANOVA) for each dependent measure and two-tailed t tests to explore planned comparisons.

Since the purpose of the open-ended questions was of an exploratory nature, a separate analysis was conducted for these data. Two independent judges, blind to group assignment, assessed subjects' responses to the open-ended questions, categorizing the responses into five dependent measures: total affective words, total words, percentage of total affective to total words, total negative affective words and total positive affective words. Interrater reliability was 0.94 for total affective words, 0.89 for negative affective words and 0.92 for positive affective words. Total words were calculated strictly by word count, and the ratio of affective to total words was then computed. The analysis was a 2 (tape, between subjects) $\times 2$ (group, between subjects) $\times 2$ (measures, within subjects) mixed design, with the five dependent measures of the open-ended response. MANOVA was used, followed by ANOVA for each dependent measure. All analyses were performed using the Statistical Package for the Social Sciences (SPSS(R)), v. 7.0 for Windows(TM), with a $p<0.05$ criterion for significance.

\section{Results}

\section{Arousal Measures}

Table 1 presents baseline and post-video means and SDs for each of three indices used to measure arousal. Repeated-measures MANOVA ( 2 tape $\times 2$ group $\times 2$ measures) revealed a significant main effect for tape $[F(3,35)=3.65, p=0.02]$, indicating an overall effect of arousal based upon the videotape viewed (neutral or arousing). There was no significant main effect for group $[F(3,35)=1.80, p=$ $0.17]$, and no significant tape $x$ group $[F(3,35)=0.83, p=0.49]$ or measure $x$ group interaction $[F(3,35)=1.18, p=0.33]$. There was a 
significant main effect for measures $[F(3,35)=11.66, p<0.001]$, indicating an arousal difference between baseline and video measures, and a significant measure $x$ tape interaction $[F(3,35)=12.87, p<$ 0.0011 ], indicating arousal differences between baseline and video conditions based upon the tape viewed. Finally, there was a 3-way interaction amongst measure, tape and group $[F(3,35)=3.41, p=$ $0.028]$, such that arousal differed from baseline to video depending both on the tape viewed and group membership. ANOVA was then used to clarify the effects of the conditions on each separate dependent measure of arousal.

Electrodermal Activity. Repeated-measures ANOVA demonstrated significant main effects of measures $[F(1,37)=14.55$, $p<0.001]$, tape $[F(1,37)=8.02, p<0.01]$ and group $[F(1,37)=$ $4.60, p<0.04]$. Thus, EDA was greater overall during the tape than at baseline, in those that received the arousal tape compared to the neutral tape, and in the high-alexithymic group compared to the lowalexithymic group. The interaction between tape and measures was also significant $[F(1,37)=23.98, p<0.001]$. The measures $x$ group, tape $x$ group, and 3-way interactions were not significant.

In order to clarify the tape $x$ measures interaction, t tests were performed. Both high- and low-alexithymic groups exposed to the arousing videotape experienced significant increases in EDA when compared to their baseline levels [high alexithymia: $\mathrm{t}(9)=-3.9, \mathrm{p}<$ 0.01 ; low alexithymia $\mathrm{t}(9)=-3.2, \mathrm{p}<0.02$ ]. In contrast, neither group exposed to the neutral videotape experienced a significant change in EDA $(p>0.25)$. These results are shown in figure 1 . The planned test analysis comparing the two groups at baseline found the high-alexithymic group's EDA was significantly higher than that of the low-- alexithymic group [t $(40)=2.2, p<0.05]$.

Psychotherapy and Psychosomatics, Vol 70, No. 2 (March/April 2001): pg. 92-102. DOI. This article is @ Karger and permission has been granted for this version to appear in e-Publications@ Marquette. Karger does not grant permission for this article to be further copied/distributed or hosted elsewhere without the express permission from Karger. 
Fig. 1. Mean EDA for high-alexithymia and low-alexithymia groups at baseline compared within the high- and low-arousal conditions. Both groups showed comparable physiological arousal response to the video stimuli. Both groups exposed to the higharousal video $(n=10$ each high and low alexithymia) demonstrated significant increases in EDA $(* \mathrm{p}<0.05)$ relative to the neutral video $(\mathrm{n}=11$ high alexithymia; $\mathrm{n}=10$ low alexithymia).

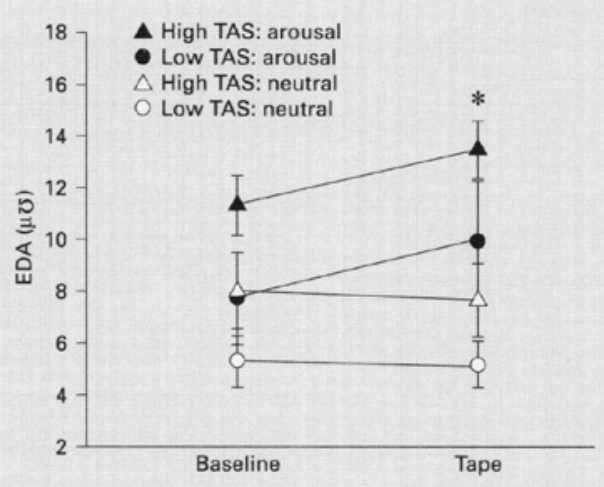

Table 1. Mean ( \pm SD) baseline and postvideo EDA, HR and EIS for between-subjects low- and high-arousal conditions for both low- and high-alexithymic participants

\begin{tabular}{|c|c|c|c|c|c|}
\hline \multirow[t]{3}{*}{ Group } & \multirow[t]{3}{*}{ Index } & \multicolumn{4}{|c|}{ Tape condition } \\
\hline & & \multicolumn{2}{|c|}{ arousal group } & \multicolumn{2}{|c|}{ neutral group } \\
\hline & & baseline & postvideo & baseline & postvideo \\
\hline \multirow[t]{3}{*}{ High alexithymia } & EDA & $11.3 \pm 3.7$ & $13.4 \pm 3.6^{*}$ & $8.0 \pm 4.8$ & $7.6 \pm 4.7$ \\
\hline & HR & $70.0 \pm 11.9$ & $73.1 \pm 11.6^{*}$ & $74.6 \pm 12.6$ & $74.2 \pm 13.1$ \\
\hline & EIS & $26.3 \pm 5.8$ & $26.3 \pm 6.2$ & $24.7 \pm 12.3$ & $21.9 \pm 12.0$ \\
\hline \multirow[t]{3}{*}{ Low alexithymia } & EDA & $7.7 \pm 5.6$ & $9.9 \pm 7.3^{*}$ & $5.3 \pm 3.2$ & $5.2 \pm 2.8$ \\
\hline & HR & $72.1 \pm 12.1$ & $75.1 \pm 11.2^{*}$ & $65.5 \pm 9.0$ & $65.8 \pm 13.2$ \\
\hline & EIS & $20.2 \pm 4.3$ & $30.8 \pm 12.2 *$ & $23.4 \pm 9.8$ & $18.9 \pm 6.7$ \\
\hline
\end{tabular}

$* \mathrm{p}<0.05$, effect based on change from baseline to postvideo.

Heart Rate. Repeated-measures ANOVA showed a significant main effect only for measures $[F(1,37)=7.1, p=0.01]$. The only significant interaction was between tape and measures $[F(1,37)=$ 7.70, $p<0.01$ ], indicating an increase in mean HR from baseline, differing in magnitude depending on the videotape viewed. There were no significant effects involving group. To clarify the interaction, t tests were performed, which showed that the arousing videotape elicited significant elevations in mean HR in both groups when compared to baseline [high alexithymia: $\mathrm{t}(9)=-4.5, \mathrm{p}<0.01$; low alexithymia: $\mathrm{t}$ (9) $=-3.9, p<0.01]$. There was no significant change in HR from baseline in either group exposed to the neutral videotape $(p>0.70)$. The baseline HR of the high-alexithymia group $(\mathrm{M}=72.44, \mathrm{SD}=$ 
12.18) was higher, but not significantly different $(p>0.10)$ from the low-alexithymia group $(M=68.80, S D=10.92)$.

EIS Scores. Repeated-measures ANOVA yielded no significant main effects $(p>0.10)$. However, there were two significant interaction effects. There was a significant interaction between tape and measures $[F(1,37)=12.35, p=0.001)$, and a significant 3-way interaction [measures $x$ tape $x$ group; $F(1,37)=5.96, p<0.02$ ]. Planned tests showed that low-alexithymic individuals reported a significant increase from baseline in EIS after viewing the arousing videotape [t $(10)=-2.51, p<0.05]$, while the high-alexithymic individuals did not [t $(9)=0.09, p>0.90]$. The change in ElS from baseline following the neutral tape was nonsignificant in both groups $(p>0.05)$. These results are depicted in figure 2 .

A post hoc t test demonstrated significantly higher baseline EIS in the high-alexithymia group, compared to the low-alexithymia group within the arousal tape condition [t $(19)=2.665, \mathrm{p}<0.05]$. However, there were no significant baseline EIS differences between the alexithymia groups in the neutral tape condition, or within the highalexithymia, low-alexithymia or high- versus low-- alexithymia groups as a whole (all $p>0.10$ ).

\section{Open-Ended Responses}

A $2 \times 2 \times 2$ repeated-measures MANOVA found no significant main effects for the between-subject independent variables tape and group, or the within-subject independent variable measures (all $p>$ 0.10 ). In addition, there were no significant tape $x$ group, group $x$ measures or tape $x$ group $x$ measures interactions (all $p>0.18$ ). However, there was a significant tape $x$ measures interaction $[F(5$, $33)=3.67, p<0.01]$, demonstrating a tape-- specific baseline to post-video change in one or more of the five indices used to measure the open-ended responses.

Table 2 presents baseline and postvideo means and SDs for each of five indices used to measure open-ended responses. Each of the five indices was submitted to repeated-measures ANOVA. Analysis demonstrated a significant main effect for measures for total words [ $F$ $(1,37)=5.64, p<0.03]$, indicating participants produced more total

Psychotherapy and Psychosomatics, Vol 70, No. 2 (March/April 2001): pg. 92-102. DOI. This article is @ Karger and permission has been granted for this version to appear in e-Publications@ Marquette. Karger does not grant permission for this article to be further copied/distributed or hosted elsewhere without the express permission from Karger. 
words post-video, as compared with baseline. There were no significant main effects for any of the four other open-ended response indices (all $p>0.24$ ). The group $x$ measures and group $x$ tape $x$ measures interactions were not significant for any of the five indices (all $p>0.10$ ). Tape $x$ measures interactions for total affect words and negative words were not significant (all $p>0.12$ ). However, three of the indices produced significant tape $x$ measures interactions: total words $[F(1,37)=14.36, p=0.001]$, positive affect words $[F(1,37)$ $=5.28, p<0.05]$ and percentage of total affect words to total words $[F(1,37)=4.54, p<0.05]$. Confirmatory t tests showed that participants exposed to the arousing videotape in both groups significantly increased their total words post-- video [high-alexithymia, $t(9)=3.25, p=0.01$; low alexithymia, $t(9)=8.80, p<0.01$ ]. Percentage of affect to total words declined in each group following arousal, but the trends were not significant by t test [high alexithymia, $\mathrm{t}(9)=2.06, \mathrm{p}=0.07$; low alexithymia, $\mathrm{t}(9)=1.98, \mathrm{p}=0.08$ ]. Positive affect words also declined post-video, but the change was not significant by t test. Interestingly, the trend differed between the groups, such that the low-alexithymia group declined $(p=0.08)$, while the high-alexithymia group showed little change $(p>0.55)$. There were no significant postvideo changes in any open-ended response indices for participants who watched the neutral videotape (all $p>$ $0.24)$.

Psychotherapy and Psychosomatics, Vol 70, No. 2 (March/April 2001): pg. 92-102. DOI. This article is @ Karger and permission has been granted for this version to appear in e-Publications@ Marquette. Karger does not grant permission for this article to be further copied/distributed or hosted elsewhere without the express permission from Karger. 


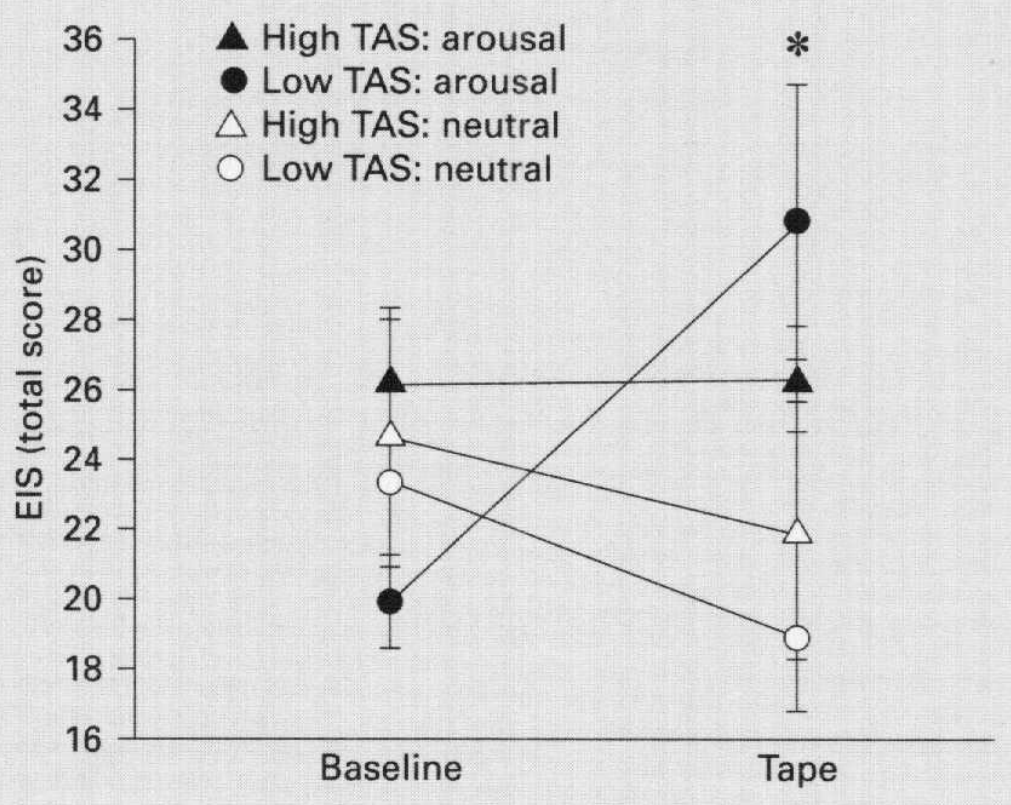

Fig. 2. Mean EIS score for high-alexithymia and low-alexithymia groups at baseline and in the high- and low-arousal conditions. Highalexithymic participants showed no subjective change in emotional response to the high-arousal condition $(\mathrm{p}<0.93)$. In contrast, lowalexithymic participants reported significantly increased subjective emotional response $(* \mathrm{p}<0.05)$.

\section{Discussion}

Martin and Pihl ${ }^{21}$ proposed that the inability to accurately identify and express emotions in alexithymia may result in prolonged, elevated levels of autonomic activation. In addition, Papciak et al. ${ }^{23}$ proposed that alexithymia may cause the decoupling of physiological from subjective responses to emotion, which may result in the inadequate regulation and resolution of neuroendocrine and autonomic responses during emotional arousal. This emotional dysregulation, ${ }^{6}$ in 
turn, may be responsible for the positive association of alexithymia with a host of stress-related disorders. ${ }^{21,23,40}$ However, initial studies have elicited mixed support for the proposed psychophysiological connection between alexithymia and illness. $23-27,31,32$ The purpose of the present study was to examine and clarify the relationship between physiological and subjective emotion recognition in high- and lowalexithymic individuals exposed to either neutral or arousing liveaction videotapes.

Based upon the previous literature, alexithymic individuals were expected to display significantly higher baseline levels of EDA and HR (physiological arousal). This prediction was supported by EDA, which was significantly higher at baseline in high-alexithymic participants. Baseline HR was also higher in high-alexithymic subjects, although the difference was not statistically significant. Thus, the present study is consistent with previous studies showing higher tonic arousal in alexithymia. ${ }^{23-26,31,32}$ Indeed, this finding has been somewhat consistent across studies, although the index by which it is shown has been inconsistent. Psychophysiological indices of arousal are complex measures; each is affected by a number of intra- and intersubject factors. Perhaps the principal reason for the inconsistency in findings across studies is such variability, along with the relatively crude methods of analysis currently used (e.g. single-point averaging of time-series data). Regardless, the present findings provide support for the stress-alexithymia hypothesis ${ }^{21}$ concerning the association between alexithymia and illness. If alexithymic individuals do not accurately recognize and identify emotional arousal, they may not initiate effective coping mechanisms to resolve arousal. Recent research provides support for an association between alexithymia and the use of less effective types of emotion-oriented and avoidanceoriented coping strategies in response to stress. ${ }^{41}$ The result of inaccurate emotion recognition could be consistently elevated levels of circulating adrenal hormones, thereby contributing to stress-related illness. ${ }^{6,21}$

The prediction that participants in both the high- and lowalexithymia groups would demonstrate a significant increase in physiological arousal while viewing the arousing videotape was supported. Although the high-alexithymia group began with an increased baseline EDA, results indicated that there was a significant

Psychotherapy and Psychosomatics, Vol 70, No. 2 (March/April 2001): pg. 92-102. DOI. This article is @ Karger and permission has been granted for this version to appear in e-Publications@Marquette. Karger does not grant permission for this article to be further copied/distributed or hosted elsewhere without the express permission from Karger. 
physiological reaction (i.e. change in EDA and HR) to the arousing videotape for both the high- and low-alexithymia groups. Viewing the neutral videotape had no significant effect on EDA or HR in either group. These findings contrast with Roedema and Simons, ${ }^{27}$ who reported decreased physiological reactions to stressors in alexithymia. However, these contrasting physiological reactions may be due to varying degrees of emotional arousal elicited by the different stimuli.

Despite the evidence of similar physiological arousal for both groups exposed to the arousing video, the results support the hypothesis that high-alexithymic participants would report significantly less change in subjective arousal than low-alexithymic participants would. That is, while the low-alexithymia group reported a significant increase in negative emotional intensity following exposure to the arousing videotape, the high-alexithymia group reported no change. Alexithymia had no significant effect in the neutral condition. In contrast, Martin and $\mathrm{Pihl}^{24}$ found alexithymia to be associated with the overreporting of subjective post-task stress levels, while Roedema and Simons ${ }^{27}$ found both a reduced physiological response during the tasks, and reduced post-task self-reported emotion words and arousal in alexithymia. Few studies to date have examined primary subjective differences between high- and low-alexithymia groups. One study reported higher levels of tension during anticipation of a stressor (i.e. at baseline), ${ }^{23}$ while another found higher subjective displeasure during post-stress relaxation. ${ }^{26}$ Therefore, while previous studies have suggested that decoupling of physiological from subjective arousal might occur in alexithymia, the present study experimentally demonstrated it, thereby supporting the hypothesis of Papciak et al. ${ }^{23}$

Psychotherapy and Psychosomatics, Vol 70, No. 2 (March/April 2001): pg. 92-102. DOI. This article is (C) Karger and permission has been granted for this version to appear in e-Publications@Marquette. Karger does not grant permission for this article to be further copied/distributed or hosted elsewhere without the express permission from Karger. 
NOT THE PUBLISHED VERSION; this is the author's final, peer-reviewed manuscript. The published version may be accessed by following the link in the citation at the bottom of the page.

Table 2. Mean ( \pm SD) baseline and postvideo open-ended question scores by between-subjects arousal conditions for both high- and low-alexithymic participants

\begin{tabular}{|c|c|c|c|c|c|}
\hline \multirow[t]{3}{*}{ Group } & \multirow[t]{3}{*}{ Index } & \multicolumn{4}{|c|}{ Tape condition } \\
\hline & & \multicolumn{2}{|c|}{ arousal group } & \multicolumn{2}{|c|}{ neutral group } \\
\hline & & baseline & postvideo & baseline & postvideo \\
\hline \multirow[t]{5}{*}{ High alexithymia } & total words & $14.3 \pm 9.9$ & $25.3 \pm 13.7^{*}$ & $10.5 \pm 10.3$ & $7.6 \pm 7.4$ \\
\hline & affect words & $2.4 \pm 1.2$ & $2.7 \pm 1.2$ & $2.2 \pm 1.3$ & $2.3 \pm 1.0$ \\
\hline & negative words & $1.1 \pm 0.7$ & $1.5 \pm 0.9$ & $1.2 \pm 1.1$ & $0.8 \pm 0.8$ \\
\hline & positive words & $1.3 \pm 1.0$ & $1.1 \pm 1.2$ & $1.0 \pm 1.2$ & $1.3 \pm 0.7$ \\
\hline & $\%$ affect to total & $31.8 \pm 31.8$ & $13.9 \pm 9.2$ & $42.6 \pm 38.1$ & $61.2 \pm 40.6$ \\
\hline \multirow[t]{5}{*}{ Low alexithymia } & total words & $15.3 \pm 9.2$ & $24.1 \pm 11.6^{*}$ & $20.4 \pm 14.3$ & $18.7 \pm 13.3$ \\
\hline & affect words & $2.6 \pm 1.1$ & $2.3 \pm 1.0$ & $2.2 \pm 1.2$ & $2.8 \pm 1.4$ \\
\hline & negative words & $0.9 \pm 1.0$ & $1.8 \pm 1.2$ & $0.7 \pm 0.7$ & $0.9 \pm 1.1$ \\
\hline & positive words & $1.8 \pm 1.2$ & $0.6 \pm 0.8$ & $1.4 \pm 1.0$ & $1.9 \pm 1.3$ \\
\hline & $\%$ affect to total & $25.8 \pm 19.4$ & $13.3 \pm 13.4$ & $29.2 \pm 38.0$ & $21.0 \pm 18.2$ \\
\hline
\end{tabular}

${ }^{*} \mathrm{p}<0.05$, based on effect of change from baseline to postvideo.

If alexithymia results in some physiological and emotion-labeling decoupling, then different types of stimuli might result in different types of decoupling. Thus, the difference between previous results and the present study may be due, in part, to the differences in stimuli. Previous studies provided stimuli that were primarily active taskoriented (e.g. timed tests, giving speeches). ${ }^{23,24,26,31}$ Indeed, Martin and $\mathrm{Pih}^{24}$ demonstrated higher 'cognitive' anxiety in alexithymia throughout testing. Perhaps this was due to the dependence of alexithymic participants on external situational cues for emotional responses, rather than to their own physiological cues. However, it has been said that subjective emotional arousal is difficult to induce in a laboratory setting because of the inability to provide truly subjective, unpleasant experiences. ${ }^{33}$ Our research used the passive viewing of videotapes with both sight and sound, similar to one other study, ${ }^{32}$ to induce subjective emotional arousal. The physiological evidence clearly showed that the subjects responded differentially to the arousing and neutral stimuli. However, high-alexithymic individuals did not report a corresponding increase in subjective intensity. During the viewing of the arousing videotape, no external cues for reaction to the stimulus were provided. Without external social or performance-related cues, the high-alexithymic individuals may not have known how to respond to their increased physiological arousal. 
Another possible explanation for decoupling in the present study is a higher emotional threshold in alexithymia. That is, alexithymic individuals may require a much greater change in physiological arousal before a change in subjective arousal is detected. Alexithymia may be the result of a neuroanatomic disconnection of the attentional from the behavioral and neurophysiological components of the emotion processing system, which could itself produce dysregulation of sympathetic responses. ${ }^{18}$ Several alexithymia theorists propose that affect-regulating capacities are facilitated by experiences with primary caregivers. ${ }^{42,43}$ Thus, aside from a neuroanatomic explanation, increased emotional threshold in alexithymia may be the result of insecure-avoidant or insecure-ambivalent attachment developed in childhood. ${ }^{31}$

It has been suggested that alexithymia may be a form of repressive coping style, ${ }^{44}$ in part, because decoupling occurs in repression. Indeed, psychophysiological research on repression shows an increased physiological response compared to self-report under 'threatening' laboratory conditions, such as delivering a self-disclosing speech. ${ }^{44}$ However, recent research has also found that repressors tend to score low on measures of alexithymia. ${ }^{45,46}$ In addition, alexithymic individuals share more similarities with highly anxious individuals, who recognize negative emotional situations, but have difficulty regulating their emotional reaction to them, ${ }^{43,45,46}$ than with repressors. Yet, alexithymic individuals are also distinguishable from highly anxious individuals because the formers endorse a minimal fantasy life and an externally orientated cognitive style. ${ }^{45}$ We suggest that the lack of situational cues in our experimental paradigm limited the ability of the externally oriented high-alexithymic group from endorsing a change in their negative emotional intensity.

Lane and Schwartz ${ }^{34}$ suggested that using a subjective questionnaire that gives names for emotions might limit emotional expression. As such, the same questionnaire may provide the labels that alexithymic individuals need to identify their emotions. Therefore, an open-ended instrument may best reveal the effects of alexithymia on emotional recognition. In order to test this hypothesis, an openended question about emotional state was given pre-and post-video, each time prior to the questionnaire (EIS). As seen by Roedema and Simons, ${ }^{27}$ it was hypothesized that high-alexithymic individuals would

Psychotherapy and Psychosomatics, Vol 70, No. 2 (March/April 2001): pg. 92-102. DOI. This article is @ Karger and permission has been granted for this version to appear in e-Publications@Marquette. Karger does not grant permission for this article to be further copied/distributed or hosted elsewhere without the express permission from Karger. 
use fewer specific emotion words in answer to the open-ended question, including fewer positive and negative affect words, than would low-alexithymic participants. This hypothesis was not supported. There were no pre- to post-video differences between the high- and low-alexithymic groups after viewing either the arousing or neutral videotape on any of the five open-ended question indices. Indeed, the only significant effects were an increase in total words, a decrease in positive affect words, and a decrease in percentage of affect to total words in both groups. There was a nonsignificant trend suggesting that the decrease in positive affect words occurred consistently in the lowalexithymic group, but this was not apparent in the high-alexithymic group.

Interestingly, many of the open-ended responses by the participants in both groups were descriptive (e.g. 'there was drilling') rather than affective (e.g. 'I was disgusted'), as was requested. The increase in total words and the high descriptive content of the answers may indicate that the arousal stimulus provided a potent cognitive stimulus that provoked an increase in thoughts and commentary about the events occurring that competed with processing of the associated arousal. Lane and Schwartz ${ }^{34}$ expressed concern that using a selfreport instrument that provides a circumscribed list of emotion labels may restrict emotional expression in non-alexithymic individuals. In contrast, a self-report measure may provide needed labels for alexithymic individuals, thereby limiting the ability to detect group differences. On the contrary, the EIS revealed group differences while the open-ended question did not. Perhaps the EIS provided needed cues for the low-alexithymic participants to overcome a potent cognitive stimulus and report the emotional changes that occurred during the arousing videotape. Neither type of instrument was beneficial for revealing emotional change in high-alexithymic participants. Therefore, the results did not support the hypothesis that an open-ended question would increase the ability to detect differences between high- and low-alexithymic groups.

In conclusion, the present findings support the hypotheses of elevated tonic sympathetic activity, as well as a decoupling between physiological arousal and the perception of negative emotional arousal in alexithymia. Two important implications of decoupling will be briefly discussed. The first is a breakdown in communication between the 
external and internal worlds of the individual. If the physiological arousal of emotions allows the individual to recognize and respond to environmental change, ${ }^{13}$ and the ability to accurately label emotion allows for the choice of an appropriate response, ${ }^{47}$ then alexithymic individuals may suffer from a breakdown in communication within themselves and with others. The breakdown in environmental communication may result in increased social isolation and subsequently decreased social support. There is evidence that alexithymia is associated with social anhedonia, ${ }^{48}$ nonverbal anger and interpersonally avoidant behavior, ${ }^{2}$ an avoidant/dismissive attachment style ${ }^{49}$ and avoidance-oriented coping. ${ }^{41}$ Because social support may be an important moderator between life stress and physical disease, ${ }^{50-}$ 55 the link between stress-related disorders and alexithymia may be a breakdown in the ability to communicate with and utilize the emotional support of others.

The second implication of the decoupling phenomenon may be for psychotherapy. As there is evidence suggesting that reduced emotional expression exacerbates physiological arousal in response to stressful situations, ${ }^{16}$ helping alexithymic individuals learn to recognize and accurately label their emotions may be the first step in reducing their risk for stress-related illness. Persons diagnosed as suffering from illnesses with stress-related components (e.g. hypertension and chronic pain disorders), who also score highly in alexithymia, may particularly benefit from interventions that focus on encouraging emotional expression and interpersonal social skills.

\section{Acknowledgments}

The authors wish to thank Kirk Erickson, Coilin O'Braonain, Theresa Williams and Douglas Yee for assistance with data collection, Dr. Pamela Schaefer for advice and assistance with stimuli and two anonymous reviewers for their helpful comments on the manuscript. This research was supported, in part, by a Summer Faculty Fellowship from the Graduate School of Marquette University (KAN). Portions of this research were presented at the 27th Annual Meeting of the Society for Neuroscience (October 1997; New Orleans, La., USA), and at the 10th Annual Meeting of the American Psychological Society (May 1998; Washington, D.C., USA).

Psychotherapy and Psychosomatics, Vol 70, No. 2 (March/April 2001): pg. 92-102. DOI. This article is C Karger and permission has been granted for this version to appear in e-Publications@Marquette. Karger does not grant permission for this article to be further copied/distributed or hosted elsewhere without the express permission from Karger. 
NOT THE PUBLISHED VERSION; this is the author's final, peer-reviewed manuscript. The published version may be accessed by following the link in the citation at the bottom of the page.

\section{References}

${ }^{1}$ Sifneos PE: Short-Term Psychotherapy and Emotional Crisis. Cambridge, Harvard University Press, 1972.

2 Berenbaum $\mathrm{H}$, Irvin S: Alexithymia, anger, and interpersonal behavior. Psychother Psychosom 1996; 65:203-208.

${ }^{3}$ Naatanen P, Ryynanen A, Keltikangas-Jarvinen L: The influence of alexithymic characteristics on the self-perception and facial expression of a physiological stress state. Psychother Psychosom 1999;68: 252262.

${ }^{4}$ Taylor GJ , Bagby RM, Parker JDA: The alexithymia construct: A potential paradigm for psychosomatic medicine. Psychosomatics 1991; 32:153164.

5 Taylor GJ, Taylor HL: Alexithymia; in McCallum M, Piper WE (eds): Psychological Mindedness: A Contemporary Understanding. Mahway, Erlbaum, 1997, pp 77-104.

6 Taylor GJ : The alexithymia construct: Conceptualization, validation, and relationship with basic dimensions of personality. New Trends Exp Clin Psychiatry 1994; 10:61-74.

${ }^{7}$ Okasha A, Ismail MK, Khalil AH, Fiki RE, Soliman A, Okasha T: A psychiatric study of nonorganic chronic headache patients. Psychosomatics 1999; 40: 233-238.

${ }^{8}$ Jula A, Salminen JK, Saarijarvi S: Alexithymia: A facet of essential hypertension. Hypertension 1999; 33: 1057-1061.

9 Bourke MP, Taylor GJ, Parker JDA, Bagby RM: Alexithymia in women with anorexia nervosa: A preliminary investigation. Br J Psychiatry 1992; 161:240-243.

10 Jimerson DC, Wolfe BE, Franko DL, Covino NA, Sifneos PE: Alexithymia ratings in bulimia nervosa: Clinical correlates. Psychosom Med 1994; 56: 90-93.

11 Pinard L, Negrete JC, Annable L, Audet N: Alexithymia in substance abusers: Persistence and correlates of variance. Am J Addict 1996; 5:32-39.

12 Cecero JJ, Holmstrom RW: Alexithymia and affect pathology among adult male alcoholics. J Clin Psychol 1997; 53:201-208.

${ }^{13}$ Clore GL: Why emotions are felt; in Ekman P, Davidson RJ (eds): The Nature of Emotion: Fundamental Questions. New York, Oxford University Press, 1994, pp 103-122.

${ }^{14}$ Dodge KA, Garber J: Domains of emotion regulation; in Garber J, Dodge KA (eds): The Development of Emotion Regulation and Dysregulation. Cambridge, Cambridge University Press, 1991, pp 3-11.

Psychotherapy and Psychosomatics, Vol 70, No. 2 (March/April 2001): pg. 92-102. DOI. This article is (c) Karger and permission has been granted for this version to appear in e-Publications@Marquette. Karger does not grant permission for this article to be further copied/distributed or hosted elsewhere without the express permission from Karger 
${ }^{15}$ Nemiah JC, Sifneos PE: Affect and fantasy in patients with psychosomatic disorders; in Hill OW (ed): Modern Trends in Psychosomatic Medicine. London, Butterworths, 1970, pp 2634.

16 Pennebaker JW, Hughes CF, O'Heeron BC: The psychophysiology of confession: Linking inhibitory and psychosomatic processes. J Pers Soc Psychol 1987; 52:781-793.

17 Pennebaker JW, Colder M, Sharp LK: Accelerating the coping process. J Pers Soc Psychol 1990; 58:528-537.

18 Lane RD, Ahern GL, Schwartz GE, Kaszniak AW: Is alexithymia the emotional equivalent of blindsight? Biol Psychiatry 1997;42:834-844.

19 Nemiah J C: Alexithymia: Present, past, and future? Psychosom Med 1996; 58: 217-218.

20 Parker JDA, Keightley ML, Smith CT, Taylor GJ : Interhemispheric transfer deficit in alexithymia: An experimental study. Psychosom Med 1999; 61: 464-468.

${ }^{21}$ Martin JB, Pihl RO: The Stress-Alexithymia Hypothesis: Theoretical and empirical considerations. Psychother Psychosom 1985; 43: 169176.

${ }^{22}$ Chrousos GP: Stressors, stress, and neuroendocrine integration of the adaptive response. The 1997 Hans Selye Memorial Lecture; in Csermely P (ed): Stress of Life: From Molecules to Man. New York, New York Academy of Sciences, 1998, pp 311-335.

${ }^{23}$ Papciak AS, Feuerstein M, Spiegel JA: Stress reactivity in alexithymia: Decoupling of physiological and cognitive responses. J Hum Stress 1985; 11: 135-142.

${ }^{24}$ Martin JB, Pihl RO: Influence of alexithymic characteristics on physiological and subjective stress responses in normal individuals. Psychother Psychosom 1986; 45:66-77.

${ }^{25}$ Wehmer F, Brejnak C, Lumley M, Stettner L: Alexithymia and physiological reactivity to emotion-provoking visual scenes. J New Ment Dis 1995; 183: 351-357.

${ }^{26}$ Friedlander L, Lumley MA, Farchione T, Doyal G: Testing the alexithymia hypothesis: Physiological and subjective responses during relaxation and stress. J New Ment Dis 1997; 185:233-239.

27 Roedema TM, Simons RF: Emotion-processing deficit in alexithymia. Psychophysiology 1999; 36:379-387.

${ }^{28}$ Apfel RJ, Sifneos PE: Alexithymia: Concept and measurement. Psychother Psychosom 1979; 32: 180-190.

29 Martin JB, Pihl RO, Dobkin P: Schalling-Sifneos Personality Scale: Findings and recommendations. Psychother Psychosom 1984;41: 145-152.

${ }^{30}$ Bagby RM, Taylor GJ, Ryan DP: The measurement of alexithymia: Psychometric properties of the Schalling-Sifneos Personality Scale. Comp Psychiatry 1986; 27:287-294.

Psychotherapy and Psychosomatics, Vol 70, No. 2 (March/April 2001): pg. 92-102. DOI. This article is (c) Karger and permission has been granted for this version to appear in e-Publications@Marquette. Karger does not grant permission for this article to be further copied/distributed or hosted elsewhere without the express permission from Karger. 
${ }^{31}$ Fukunishi I, Sei H, Morita Y, Rahe RH: Sympathetic activity in alexithymics with mother's low care. J Psychosom Res 1999;46:579-589.

32 Infrasca R: Alexithymia, neurovegetative arousal and neuroticism. Psychother Psychosom 1997: 66:276-280.

${ }^{33}$ Ahrens S, Deffner G: Empirical study of alexithymia: Methodology and results. Am J Psychother 1986; 15:430-447.

${ }^{34}$ Lane RD, Schwartz GE: Levels of emotional awareness: A cognitivedevelopmental theory and its application to psychopathology. Am J Psychiatry 1987; 144:133-143.

35 Bagby RM, Parker JDA, Taylor GJ : The twenty-item Toronto Alexithymia Scale. I. Item selection and cross-validation of the factor structure. J Psychosom Res 1994; 38:23-32.

${ }^{36}$ Bagby RM, Taylor GJ, Parker JDA: The twenty-item Toronto Alexithymia Scale. II. Convergent, discriminant, and concurrent validity. J Psychosom Res 1994; 38: 33-40.

37 Schaefer P: The Effects of Ability to Express Emotion on Physiological and Verbal Responses to Emotionally-Laden Stimuli; Psychology. Milwaukee, University of Wisconsin - Milwaukee, 1994.

38 Schwartz GE: Emotion and psychophysiological organization: A system approach; in Coles MGH (ed): Psychophysiology: Systems, Processes and Applications. New York, Guilford Press, 1986, pp 354-377.

39 Taylor G, Doody K, Newman A: Alexithymic characteristics in patients with inflammatory bowel disease. Can J Psychiatry 1981;26: 470474

40 Nemiah JC: Physiological changes and clinical events during psychotherapy: Commentary. Integr Psychiatry 1985; 3: 175-176.

${ }^{41}$ Parker JDA, Taylor GJ , Bagby RM: Alexithymia: Relationship with ego defense and coping styles. Comp Psychiatry 1998;39:91-98.

42 Krystal H: Desomatization and the consequence of infantile psychic trauma. Psychoanalyt Inq 1997; 17: 126-150.

43 Taylor GJ , Bagby RM, Parker JDA: Disorders of Affect Regulation: Alexithymia in Medical and Psychiatric Illness. Cambrige, Cambridge University Press, 1997, pp 359.

${ }^{44}$ Bonanno GA, Singer JL: Repressive personality style: Theoretical and methodological implications for health and pathology; in Singer J L (ed): Repression and Dissociation: Implications for Personality Theory, Psychopathology, and Health. Chicago, University of Chicago Press, 1990, pp 435-470.

${ }^{45}$ Newton T, Contrada RJ : Alexithymia and repression: Contrasting emotionfocused coping styles. Psychosom Med 1994;56:457-462.

46 Myers LB: Alexithymia and repression: The role of defensiveness and trait anxiety. Pers Indiv Diff 1995; 19:489-492.

${ }^{47}$ Lazarus RS: Emotion and Adaptation. New York, Oxford University Press, 1991, p 557.

Psychotherapy and Psychosomatics, Vol 70, No. 2 (March/April 2001): pg. 92-102. DOI. This article is (c) Karger and permission has been granted for this version to appear in e-Publications@Marquette. Karger does not grant permission for this article to be further copied/distributed or hosted elsewhere without the express permission from Karger. 
NOT THE PUBLISHED VERSION; this is the author's final, peer-reviewed manuscript. The published version may be accessed by following the link in the citation at the bottom of the page.

48 Prince JD, Berenbaum H: Alexithymia and hedonic capacity. J Res Pers 1993; $27: 15-22$.

${ }^{49}$ Scheidt CE, Walter E, Schnock C, Becker-Stoll F, Zimmermann P, Lucking $\mathrm{CH}$, Wisching $\mathrm{M}$ : Alexithymia and attachment representation in idiopathic spasmodic torticollis. J New Ment Dis 1999; 187:47-52.

50 Holahan CJ, Moos RH, Holahan CK, Brennan PL: Social context, coping strategies, and depressive symptoms: An expanded model with cardiac patients. J Pers Soc Psychol 1997; 72: 918-928.

51 House JS, Landis KR, Umberson D: Social relationships and health. Science 1988; 241: 540-545.

52 Lane RD, Sechrest L, Reidel R, Weldon V, Kaszniak A, Schwartz GE: I mpaired verbal and nonverbal emotion recognition in alexithymia. Psychosom Med 1996; 58: 203-210.

53 Salovey P, Bedell BT, Detweiler JB, Mayer JD: Coping intelligently: Emotional intelligence and the coping process; in Snyder CR (ed): Coping: The Psychology of What Works. New York, Oxford University Press, 1999, pp 141164.

54 De J ong GM, van Sonderen E, Emmelkamp PMG: A comprehensive model of stress. The roles of experienced stress and neuroticism in explaining the stress-distress relationship. Psychother Psychosom 1999;68: 290298.

55 Ryff CD, Singer BH: Biopsychosocial challenges of the new millennium. Psychother Psychosom 2000; 69: 170-177.

Psychotherapy and Psychosomatics, Vol 70, No. 2 (March/April 2001): pg. 92-102. DOI. This article is @ Karger and permission has been granted for this version to appear in e-Publications@Marquette. Karger does not grant permission for this article to be further copied/distributed or hosted elsewhere without the express permission from Karger. 